\title{
A Case Report: Transcatheter Coil Embolisation for Coronary Artery Fistula from Left Anterior Descending Artery and Drainage to Right Ventricle
}

\author{
Dr. Sainath Hegde ${ }^{1}$, Dr. Prashant Udgire ${ }^{2}$ \\ ${ }^{1}$ Registrar, Dept of Cardiology, MGM Hospital, Aurangabad, India \\ ${ }^{2}$ Assistant Professor, Dept of Cardiology, MGM Hospital, Aurangabad, India
}

\begin{abstract}
Coronary artery fistulae (CAF) represent the most frequent congenital anomalies influencing hemodynamic parameters of coronary arteries. Determining the optimal management of symptomatic patients with CAF still remains a challenging problem, and has been traditionally considered as an indication for cardiac surgery. The use of transcatheter coil embolization for CAF has emerged as a less invasive strategy and has recently been considered as an alternative to surgical correction.
\end{abstract}

Keywords: Aneurysm, Angina pectoris, Coil embolisation, Coronary artery fistulae, Transcatheter closure.

\section{Introduction}

Coronary arteriovenous fistula (CAVF) is rare anomaly which consists of abnormal communication between coronary artery and one of the cardiac chambers or vessels adjacent to the heart. Coronary arteriovenous fistulas (CAVFs) are present in $0.002 \%$ of the general population and are visualized in nearly $0.25 \%$ of patients undergoing catheterization. ${ }^{(1-5)}$

Small fistulas usually do not cause any hemodynamic compromise. However, the larger fistulae can cause coronary artery steal phenomenon, which leads to ischemia of the segment of the myocardium perfused by the coronary artery.

Exact etiologies of CAFs have not been identified. They are usually congenital or acquired. The congenital causes are responsible for most of them. The acquired causes of CAFs include coronary atherosclerosis, Takayasu arteritis, polymyositis, cardiac surgery, percutaneous coronary intervention, septal myomectomy, closed-chest ablation of accessory pathway, permanent pacemaker placement, transbronchial lung biopsy, acute myocardial infarction, and after repeated myocardial biopsies in cardiac transplantation. The penetrating and nonpenetrating chest trauma may also lead to CAF.

In adults, fistulae are usually discovered by chance during coronary angiography. Currently, immediate percutaneous closure is preferred and surgical closure is reserved for multiple or larger fistulae. Percutaneous balloon or coil occlusion has been safely and efficiently performed since more than a decade ago and has become the first choice therapeutic option. ${ }^{(6)}$

We describe a patient with an unusual type of fistula of the left anterior descending to the right ventricle, which was revealed at cardiac catheterization and its reversal post coil occlusion.

\section{Case Report}

A 40 year old female who presented with exertional pressure type retrosternal chest pain and gradually progressive dyspnoea over a period of one month. She had no positive family history for any cardiac ailments.

Physical Examination revealed normal vital signs and no cardiac murmur. The electrocardiography showed inferior/lateral ST segment depression and normal cardiac enzymes. A posteroanterior X-ray of chest showed only mild cardiomegaly.

Transthoracic Coronary angiography revealed a tortuous and ectatic left anterior descending artery with multiple small arteriovenous fistula draining into the right ventricle without evidence of atherosclerothic narrowing of the coronary arteries (Figure 1). The patient was unsucessesfully treated as a case of unstable angina at various institutes with antiplatelets, statins and nitrates. Following diagnosis of the congenital coronary fistula, she underwent successful coil occlusion at our institute (Figure 2). The fistula was sealed with a total of six $6 \mathrm{~mm} \times 4 \mathrm{cms}$ hilal microcoils by utilising a 0.018 universal wire and a progreat microcatheter via the left anterior descending artery.

\section{Discussion}

Anatomic characteristics of fistulas vary between different studies. Earlier studies report right coronary system as the most frequent site of origin, while more recent studies suggest that the left system may be the more common site. Most common sites of drainage include right ventricle and pulmonary artery. Left-sided chambers of the heart are less likely to be the draining site. ${ }^{(7)}$

Currently, microcoil embolisation is considered the predominant method for transcatheter closure, and recent developments in catheter and coil technologies have made it a safe procedure. ${ }^{(8)}$ 


\section{International Journal of Science and Research (IJSR) \\ ISSN (Online): 2319-7064}

Index Copernicus Value (2013): 6.14 | Impact Factor (2015): 6.391

Close long-term follow-up with coronary angiography and myocardial scintigraphy after transcatheter closure of the CAF is very important. Recently, transcatheter closure techniques have also been suggested as an effective alternative to cardiac surgery for certain select patients, particularly when a single drainage site is documented. However, limited data are available regarding the long-term results of percutaneous management of patient $\mathrm{CAF}$ as a course of treatment CAFs are rare cardiac anomalies, but they should always be part of differential diagnosis of symptoms of chest pain and dyspnoea, especially in patients without significant risk factors for acquired cardiac disease. They can give rise to a variety of symptoms because of their hemodynamic consequences or complications. Correction of $\mathrm{CAF}$ is indicated if the patients are symptomatic or if other secondary complications develop. We described here a unique case with a symptomatic congenital CAF originating from the $\mathrm{LAD}$ and draining into the RV. The patient underwent successful transcatheter closure of the fistula using a microcoil embolisation technique and was relieved of all her symptoms.

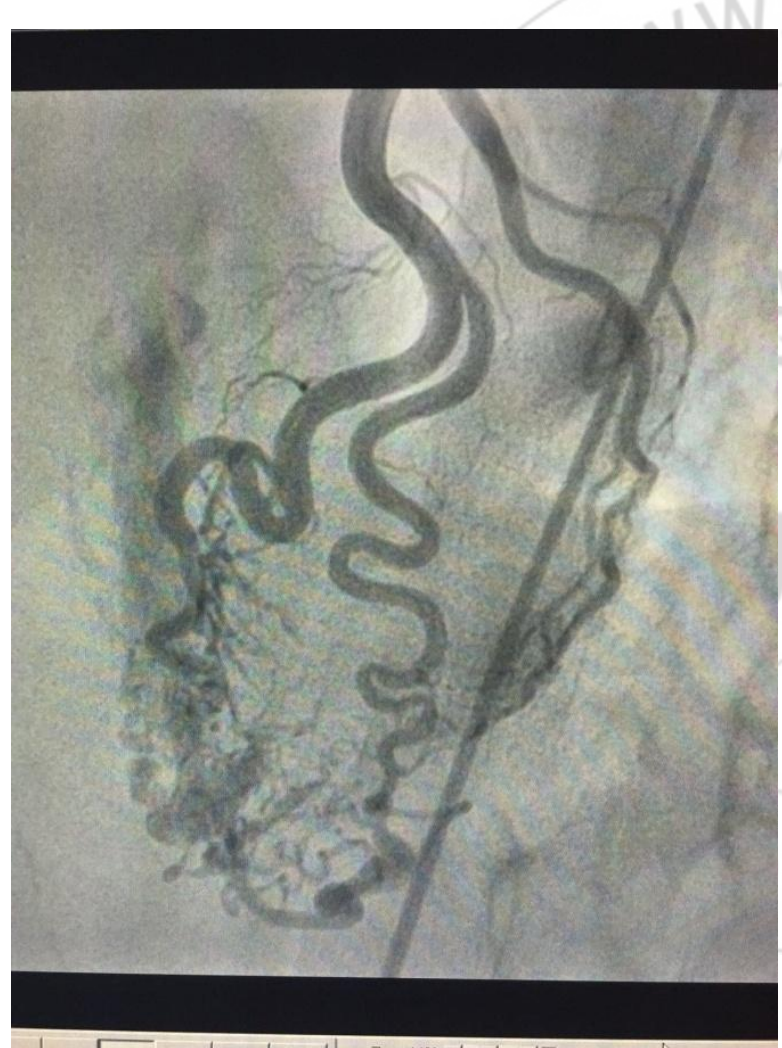

Figure 1: Diagnostic coronary angiography of the left coronary artery showing the large, tortuous fistula, originating from the left anterior descending artery (Diagonal) and terminating into the right ventricle

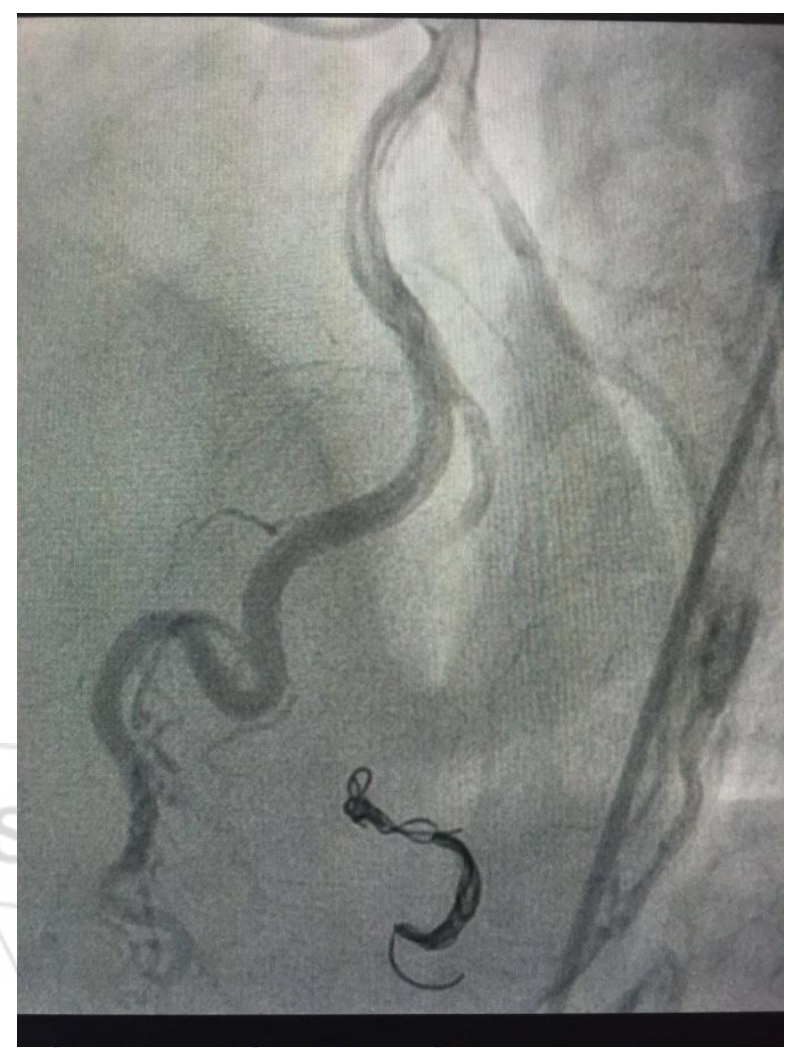

Figure 2: Multiple microcoils have been deployed to occlude the fistula

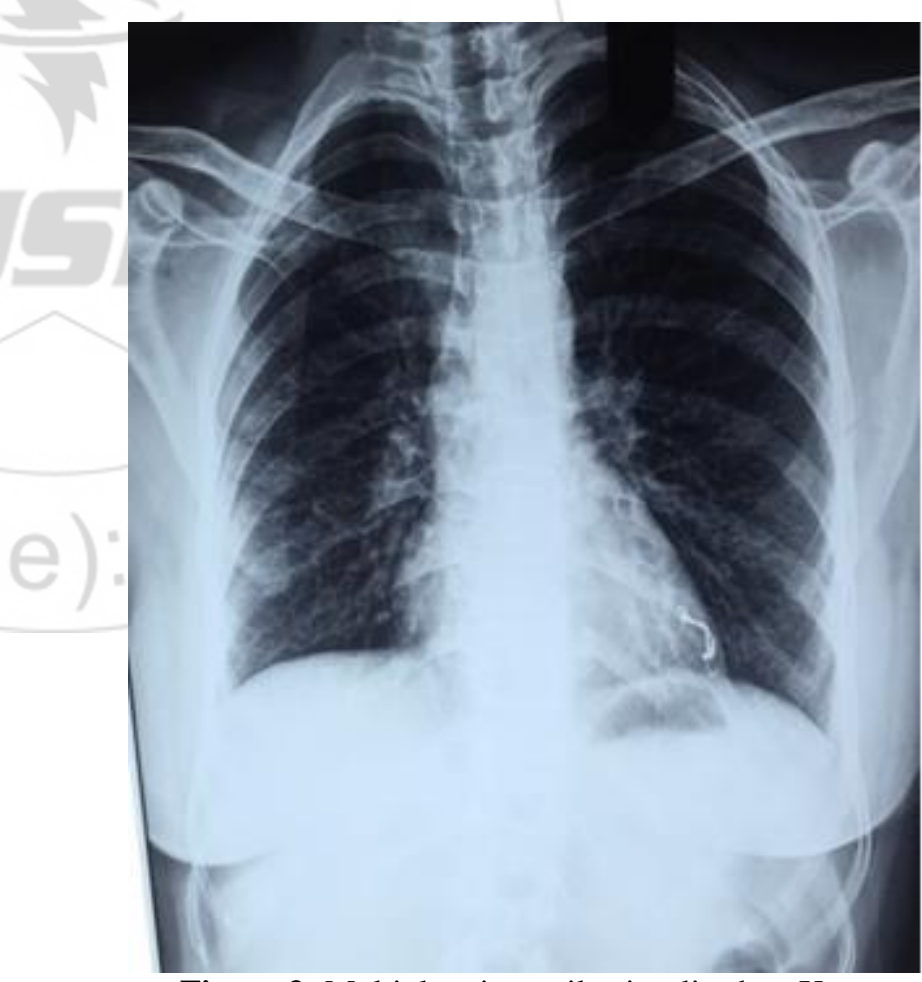

Figure 3: Multiple microcoils visualised on Xray

\section{References}

[1] Fernandes ED, Kadivar H, Hallman GL, Reul GJ, Ott DA, Cooley DA: Congenital malformations of the coronary arteries: the Texas Heart Institute experience.

[2] Ann Thorac Surg 1992, 54:732-740. 


\section{International Journal of Science and Research (IJSR) \\ ISSN (Online): 2319-7064}

Index Copernicus Value (2013): 6.14 | Impact Factor (2015): 6.391

[3] Olearchyk AS, Runk DM, Alavi M, Grosso MA: Congenital bilateral coronary-to-pulmonary artery fistulas.

[4] Ann Thorac Surg 1997, 64:233235. PubMed Abstract | Publisher Full Text

[5] Urrutia-S CO, Falaschi G, Ott DA, Cooley DA: Surgical management of 56 patients with congenital coronary artery fistulas.

[6] Ann Thorac Surg 1983, 35:300-307. PubMed Abstract

[7] Dodge-Khatami A, Mavroudis C, Backer CL: Congenital Heart Surgery Nomenclature and Database Project: anomalies of the coronary arteries. Ann Thorac Surg 2000, 69:270-297.

[8] Gowda RM, Vasavada BC, Khan IA: Coronary artery fistulas: clinical and therapeutic considerations.Int $\mathrm{J}$ Cardiol 2006, 107:7-10.

[9] Qureshi SA, Tynan M. Catheter closure of coronary artery fistulas. J Interv Cardiol. 2001;14:299-307.

[10] R.E. Hobbs, H.D. Millit, P.V. Raghavan, D.S. Moodie, W.C. Sheldon Coronary artery fistulae: a 10-year review Cleve Clin Q, 49 (4) (1982), pp. 191-197

[11] Armsby LR, Keane JF, Sherwood MC, et al. Management of coronary artery fistulae. Patient selection and results of transcatheter closure. J Am Coll Cardiol 2002;39:1026-32.

[12] Collins N, Mehta R, Benson L, et al. Percutaneous coronary artery fistula closure in adults: technical and procedural aspects. Catheter Cardiovasc Interv 2007;69:872-80. 